\title{
Australian evidence on the role of interregional flows, production capacity, and generation mix in wholesale electricity prices and price volatility
}

\author{
Helen Higgs ${ }^{\mathrm{a}}$, Gudbrand Lien ${ }^{\mathrm{b}}$, Andrew C. Worthington ${ }^{\mathrm{a}, *}$, \\ ${ }^{a}$ Department of Accounting, Finance and Economics, Griffith University, Nathan, Australia \\ b Norwegian Agricultural Economics Research Institute and Lillehammer University College, Lillehammer, \\ Norway
}

\begin{abstract}
This paper examines the impact of interregional flows, production capacity and generation mix, encompassing both fossil fuels (black and brown coal and natural gas) and renewables (hydropower and wind power), on daily wholesale electricity price volatility across the five regional electricity markets in the Australian National Electricity Market from January 2006 to June 2012. One objective is to examine the volatility impacts of daily interregional energy flows when regions are exporting and importing electricity and daily slack (excess daily capacity) produced by differences in generation capacity and actual generation. Another is to gain insights into the emergent effects of policy and industry developments regarding the choice of generation on price volatility. Using panel common and fixed-effects generalized autoregressive conditional heteroscedasticity (GARCH) specifications, we find that the type of generation exerts a strong influence on prices and price volatility, with prices increasing for open-cycle gas turbine and hydro generation and decreasing for black coal generation. We also find increasing price volatility for black coal, open-cycle gas turbine, and hydro generation, and decreasing price volatility for combined-cycle gas turbine generation. Interregional flows appear to exert no significant influence on prices or price volatility, while generation slack tends to reduce prices, but has no effect on price volatility.
\end{abstract}

\section{JEL classification:}

C33

D40

Q41

Q48

Keywords:

Electricity generation

Generation mix

Generation capacity

Regional interconnection

Price and price volatility

Panel common and fixed effects GARCH 



\section{Introduction}

In just over a decade, the electricity industry in Australia has experienced rapid and farreaching changes in market structure, operations, competitiveness, ownership, and efficiency. Once characterized by large vertically integrated state government-owned entities operating in distinct regional markets, it now features the separation of generation, transmission, and distribution functions across a relatively large number of competing commercialized, privatized, and private companies with strong interregnal linkages. A small but growing literature has examined price behaviour in these markets, including Higgs and Worthington (2005), Worthington et al. (2005), Chan and Gray (2006), Becker at al. (2007) and Higgs (2009).

Alongside these developments have been important changes in the technologies used to produce and distribute electricity in Australia. Obviously, the high-voltage interconnectors between the state-based regions in the national electricity market have been critical, with Tasmania physically joined to the mainland market through an unregulated interconnection with Victoria (Basslink) and regulated interconnectors between the four mainland states. In addition, electricity generation capacity has also increased significantly in all regions and across all technologies over time. Even during the relatively short period since the creation of the National Electricity market (NEM) in 1998, yearly electricity generation in Australia increased by some 35,411 GWh (22\%). However, of late and for at least the next few years, there has been a continuing slide in electricity demand, with both falling industrial demand resulting from the closure of aluminium smelters and manufacturing operations and softening retail demand associated with household solar generation. The current situation is of oversupply in the NEM, even beyond the $15-20 \%$ reserve margin commonly set to ensure continuity in supply.

Endowed with substantial reserves of black and brown coal, for much of its history and today, the Australian electricity industry has drawn on solid fossil fuels to provide most of its capacity and generated electricity, especially base load production. For instance, of the 195,525 GWh of electricity generated in Australia in 2013, black and brown coal accounted for 97,509 GWh (50\%) and 47,255 GWh (24\%), respectively (AEMO, 2015). While the share of coal in total generation has clearly declined over time, down from $88 \%$ for both black and brown coal in 1998, it is still up by 3,573 GWh in volume during our chosen sample period. 
More recently, the development of sizeable gas reserves, both natural and coal seam gas (CSG), in South Australia, Queensland, NSW, and elsewhere has widened the choice of fossil fuels in use, especially in peaking plants, such that it now accounts for $22,693 \mathrm{GWh}(12 \%)$ of total electricity generation. This is a nearly ninefold increase from the bare 2,541 GWh of gas-fired electricity generation in 1998, which at the time accounted for less than $2 \%$ of total electricity production. With emissions of greenhouse gases (GHGs) less than half those from brown and black thermal coal, gas has lower capital costs than coal-fired plants, but higher fuel costs. During the period of our analysis, growth in gas-fired electricity generation surged alongside the discovery of new and larger gas reserves, though the discovery of new reserves has now slackened with gas-fired generation itself expected to soften alongside electricity demand (Fleming and Measham 2015)

Lastly, renewable energy production of all types has also increased in volume and share, but rather more moderately, from 15,861 GWh (10\%) in 1998 to 28,068 GWh (14\%) in 2013 (an increase of $76 \%$ over the past 17 years). In practice, this is mostly hydropower from the Snowy Mountains Hydroelectric Scheme (about 55\% of hydropower production) and Tasmania (an additional 29\%), with smaller-scale operations in some of the other states. However, wind power has recently emerged as a primary and growing source of renewable energy in Australia, primarily in South Australia and Victoria. While relatively insignificant at the national level, South Australia now has wind energy production comparable to Denmark and exceeding that of Spain and Germany. In fact, on a number of occasions, wind (along with solar) electricity production in South Australia has exceeded its own regional demand.

In terms of other renewable sources of wholesale electricity, the first commercial-scale photovoltaic (PV) solar power plants opened outside the NEM in Western Australia and the Northern Territory in the early 2010s, with commercial-scale plants within the NEM (at Nyngan and Broken Hill) coming online in the second half of 2015. Of course, while not part of the NEM, the huge expansion in household PV solar systems (currently in excess of one million domestic household installations and nearly $4 \mathrm{GW}$ of installed capacity) has already had a significant impact on the wholesale market, in terms of reducing electricity demand and delaying the development of large-scale generation capacity. A number of renewable technologies also show future promise (though none are presently commercial viable) as potential wholesale suppliers of electricity in Australia, including tidal/wave, bioenergy, and geothermal generation. There are currently no plans for nuclear generation in Australia. 
However, apart from the existing and newly discovered natural resource endowments that have done much to foster the existing generation mix in the Australian electricity industry, the pattern of generation technologies is also evolving in response to climate change policy. Most notable of these is the Commonwealth government's primary emissions reduction policy in the form of a national renewable energy target (RET) scheme intended to deliver a $20 \%$ share of renewable energy in Australia's generation mix by 2020 through the requirement for electricity retailers to source a proportion of their electricity from renewable sources developed after 1997.

More recently, July 2012 saw the introduction of a carbon tax of $\$ 23$ per ton of emitted $\mathrm{CO}_{2}$ on fossil fuels consumed by major industrial emitters as a complement to the RET. This fixed price was to increase by $5 \%$ per year until transitioning to a flexible-price emissions-trading scheme (ETS) in 2015/16 when the permits available would be set in line with a pollution cap. While the carbon tax was abolished on 1 July 2014 by the current Liberal-National government, it was replaced by a so-called 'direct action plan' comprising an emissions reduction fund intended to provided financial incentives for polluters to reduce GHG emissions.

While the effects of these changes remain contentious, it was generally accepted that the RET and the carbon tax then direct action, would continue to drive the development of lowemission renewable generation at the expense of high-emission fossil-fuel generation. However, there is substantial uncertainty over the timing and technical and economic feasibility of these changes with it being likely that coal will remain the dominant baseload generation type for at least the next decade, and gas increasingly, and almost paradoxically, called upon to complement the variable and intermittent output from wind as the primary renewable after hydropower. It is clear that while wholesale prices are now stable and not directly accountable for recent large increases in retail prices-Simshauser and Nelson (2013) provide a useful analysis of the causes and past and immediate impacts - they will respond to the varying cost structures of the different technologies, combined with the impact of generation capacity and regional interconnection.

The purpose of this paper is to use existing data from the operation of the Australian NEM to gain insights into the effect of these very long-term changes in generation capacity, regional interconnection, and generation mix on wholesale electricity prices. Fortunately, the Australian market comprises distinct regional markets, each characterized by its own peculiar generation and distribution characteristics. Using panel data techniques and relatively high- 
frequency data, we can then provide meaningful estimates of their effects using both the substantial cross-sectional variation across regions and any time-series variation.

The structure of the remainder of the paper is as follows. Section 2 briefly discusses the Australian electricity market. Section 3 describes the data used and the variables specified, while Section 4 details the empirical model specification. Section 5 contains the results and Section 6 concludes.

\section{Australian national electricity market}

Established in December 1998, the NEM encompasses the five state-based regional markets of New South Wales (NSW), Queensland (QLD), South Australia (SA), Tasmania (TAS) and Victoria (VIC) operating as an interconnected grid coordinated by the Australian Energy Market Operator (AEMO). At present, the NEM, with a registered capacity of about 50,000 MW, annually provides about $200 \mathrm{TWh}$ of electricity worth $\$ 11.4$ billion to almost nine million businesses and households. Key market participants other than the market operator are the nearly 200 large publicly and privately owned generators, the five state-based transmission networks (linked by cross-border interconnectors), 13 major distribution networks, and up to 30 electricity retailers in each of the five regions.

A system of regional interconnectors (both regulated and unregulated) is used to import and export electricity into and from regions when demand in an adjoining region exceeds local supply or when the price of electricity in an adjoining region is so low as to displace local supply. The market determines a separate price for each region, with the regions typically operating as an 'integrated' market with price alignment about 60-80 percent of the time (ACCC 2011). For the remaining 20-40 percent of the time, the regional markets operate separately because interregional power transmission is very much constrained by the physical transfer capacity of the regional interconnectors and the physical losses experienced through transmission over the long distances between regions. Simshauser and Nelson (2013) provide a useful simple discussion of the impact on prices of the changing patterns of energy demand and supply in the NEM through the analysis of load-duration curves.

In each regional market, generators are required to submit bidding schedules on a half-hourly day-before basis. Matching expected demand in the next five minutes against the bid stack for that half-hour period sets prices and the price offered by the last generator (plant are dispatched on a least-cost basis) to meet total demand sets the five-minute price. The pool price is the time-weighted average of the six five-minute periods comprising each half-hour 
trading period. This is the price generators receive for the electricity they dispatch into the pool, and is the price customers pay to receive generation in that half hour period. Spot prices currently range between a floor price of $-\$ 1,000$ per MWh and a cap of $\$ 13,800$ per MWh. For a typical retail electricity bill in Australia, generation costs make up about 20\%, network costs around $51 \%$, retail costs $20 \%$, and the carbon price (until its abolishment) about $9 \%$ (Garnaut 2011; AEMO 2015)

A number of characteristics, including climate, geography, history, demography, and economics, have combined to create a system of electricity markets in the NEM with strong regional features. In terms of consumption, NSW accounts for about 37 percent of total NEM consumption, QLD and VIC each have about 25 percent, SA about 6 percent and TAS less than 5 percent. With generation, black and brown coal represent about 58 percent of technical capacity (but 80 percent of generation) across the NEM, but disproportionally more in NSW, QLD, and VIC, while gas-fired production represents 10 percent of generation (about half that of the installed capacity), though this is concentrated in SA. Hydroelectric generation (in NSW, VIC, and TAS) accounts for around 16 percent of registered capacity, but less than 6 percent of output. Lastly, wind currently represents only about 3 percent of capacity and 2 percent of output across the NEM. In terms of the import and export of electricity to and from other regions, in recent years NSW, SA and TAS have been mostly net importers whereas QLD and VIC are mostly net exporters. Combined together, prices vary significantly across the regions and time, with prices being generally higher in NSW, SA, and TAS and lower in QLD and VIC.

\section{Data and descriptive statistics}

The data employed in this study principally consists of daily spot electricity prices $(P C E)$ and natural logarithm of the spot price (LNPCE) [in Australian $\$ / \mathrm{MWh}$ ] and the volume of demand $(V O L)$ [in 10,000 MWh] from January 1, 2006 to 6 September 2012 for each of the five wholesale electricity markets in the NEM. All data are from the Australian Energy Market Operator (AEMO, 2012). All price data were originally on a half-hourly basis representing the 48 trading intervals in each 24-hour period, which we simply average (i.e. not load weighted) to obtain the daily average price and total daily demand. By way of comparison, De Vany and Walls (1999a; 1999b), Robinson (2000), Lucia and Schwartz (2002), Escribano et al. (2002), Solibakke (2002), Higgs and Worthington (2005), Worthington et al. (2005), Chan and Gray (2006), Koopman et al. (2007), Becker et al. 
(2007) and Higgs (2009) also employ daily spot prices. Higgs and Worthington (2010) provide a useful review of past approaches.

Data for daily generation by type, available capacity for each generator and inter-regional flow are from Global Roam (2012). Daily generation [in 1,0000 MWh] for each regional electricity market is presented for black coal (BKCL), brown coal $(B N C L)$, gas $(C C G T$ and $O C G T), H Y D R$ and WIND generators. The daily inter-regional energy flow (FLOW) for each region is positive if the region is exporting electricity and negative if the region is importing electricity. The difference between the daily available generation capacity and the actual generation produces the daily slack $(S L K)$ or excess daily capacity. Karakatsani and Bunn (2010) defined the slack as margin or excess generation capacity and an indicator of scarcity. We pool the data for the five regional markets to form a balanced panel of 12,205 observations.

Table 1 presents descriptive statistics of the daily spot electricity prices $(P C E)$, the natural logarithm of the daily spot electricity prices ( $L N P C E)$, generation $(G E N)$ : such as $B N C L$, $B K C L, C C G T, O C G T, H Y D R$, and WIND, FLOW and SLK for each regional market and the panel data. The average pooled price across the five regional markets is $\$ 42.07$ with a standard deviation of $\$ 84.19$ ( $\$ / \mathrm{MWh}$ ). The spot electricity prices for the five markets range from $\$ 38.45 / \mathrm{MWh}(\mathrm{QLD})$ to $\$ 48.96 / \mathrm{MWh}(\mathrm{SA})$. The highest average spot electricity prices are in SA $(\$ 48.96 / \mathrm{MWh})$, TAS $(\$ 42.02 / \mathrm{MWh})$ and NSW $(\$ 41.42 / \mathrm{MWh})$. The standard deviations of spot electricity prices range from $\$ 44.77$ (TAS) to $\$ 132.24$ (SA).

\section{<TABLE 1 HERE >}

The distributional properties of the pooled and regional electricity prices appear non-normal. All of the markets are significantly positively skewed ranging from 10.04 (TAS) to 19.88 (VIC) with the pooled skewness indicating the greater likelihood of large price increases than price falls. The kurtosis, or degree of excess, is also large, ranging from 144.43 for TAS to 514.33 for VIC, and as the kurtosis, or degree of excess, in all of these electricity markets exceeds three, there is an indication of leptokurtic (fat-tailed) distributions. The calculated Jarque-Bera statistic and corresponding p-value in Table 1 test the null hypotheses that the distribution of spot electricity prices is normally distributed. All $p$-values are $<0.01$ level of significance, thereby rejecting the null hypothesis.

We use two tests of panel unit roots to test for stationarity: the Levin, Lin and Chu (LLC) tstatistic and $p$-value are -39.2075 and $<0.01$ and the Im, Pesaran and Shin (IPS) W-stat and $p$ - 
value are -40.8734 and $<0.01$, respectively. Both unit root tests reject the null hypothesis of non-stationarity or a unit root at the 0.01 level of significance, so the panel spot electricity price series is stationary. We obtain similar results for all of the generation mix variables, FLOW and SLK, as shown in Table 2. We thus concur with Lucia and Schwartz (2002), Higgs and Worthington (2005), Worthington et al. (2005), and Higgs (2009) that wholesale electricity prices are stationary.

NSW and QLD have black coal base generators. The average daily electricity generation in NSW consists of 181234 MWh of BKCL, 6326.1470 MWh CCGT, 5844.2350 MWh HYDR, 706.9253 MWh WIND and 565.0101 MWh OCGT. The QLD average daily generation is 134650.3000 MWh in BKCL, 14103.3500 MWh in CCGT, 6619.8740 MWh in OCGT and 2236.3630 MWh in HYDR. The daily generations in SA are $18353.9200 \mathrm{MWh}$ in CCGT, 11847.9100 MWh in BNCL, 5829.8530 MWh in WIND and 1014.0940 MWh in OCGT. The high gas generation results in high spot electricity prices in SA. In VIC, 139728.0000 MWh of electricity is generated by BNCL, 6669.4350 MWh by HYDR, 2363.7920 MWh by CCGT, 2010.0610 MWh by OCGT and 1934.3980 MWh by WIND. TAS has 2969.5390 MWh of its generation by CCGT, 22951.5800 MWh by HYDR and 1050.7660 MWh by WIND and 138.5216 MWh by OCGT.

With interconnectivity across regional spot electricity markets in the NEM, Table 1 also presents the average daily inter-regional quantity flows. Overall, the pooled market imports on average 523.88 MWh. On average NSW, SA and TAS import respectively 21271.72 MWh, 2160.00 MWh, and 2852.55 MWh of electricity from interconnected regions on a daily basis, while QLD and VIC export respectively 15466.75 MWh and 8198.11 MWh per day to other regional markets. Over this sample period, NSW imported on average 21271.72 MWh of electricity from QLD and VIC with the highest daily inter-regional import of 55252.00 MWh and export of 6641.5 MWh while QLD exports on average 15466.75 MWh of electricity to NSW with a maximum daily export of 30281.50 MWh.

Lastly, according to the slack or excess capacity, NSW, OLD and VIC have the highest average slack of 99543.44 MWh, 75764.17 MWh and 69641.48 MWh, respectively, while SA and TAS, which depend on gas and renewables have the lowest average slack of 30101.66 and 29516.96, respectively. 


\section{Model specification}

The dependent variable is the natural logarithm of the panel daily wholesale spot electricity prices. The first two independent variables specified are the lagged price and contemporaneous volume of demand $(V O L)$. We hypothesise a positive sign when the contemporaneous volume of demand is regressed against price. The next group of independent variables is the six types of electricity generation, comprising black coal $(B K C L)$, brown coal (BNCL), combined-cycle gas turbines (CCGT), open-cycle gas turbines (OCGT), hydro (HYDR) and wind (WIND). SA and VIC use BNCL as their base load generators, whereas NSW and QLD employ the relatively cleaner alternative of $B K C L$ coal. All regions embrace some form of renewables in the form of HYDR and/or WIND. All other things being equal, we expect the spot price to decrease for the cheaper technologies of $B N C L$ and $B K C L$ generation and increase for CCGT, OCGT, HYDR and WIND.

In terms of flow, we expect increasing $F L O W$ to be associated with price increases as regional generation proves insufficient to meet demand and electricity is imported from other regions. As $S L K$ or excess capacity, we expect this to have a negative impact on electricity price. In addition to the variables of interest, we also include in our specifications cariables intended to reflect the strong seasonality and timing of electricity demand in the form of dayof-week and month-of-year dummy variables (descriptive statistics not shown). For example, Solibakke (2002) found that price volatility in the Nordic spot electricity market increased strongly on Mondays and Saturdays and were especially strong during May, June and July. Herbert (2002) also presented evidence of seasonality in electricity price risk which increased in the summer and winter months. And Hadsell et al. (2004) found that price and volatility behavior differed by month across US electricity markets.

The first methodological requirement is to remove the predictable component of spot electricity prices so as to produce a spot electricity price innovation, $e_{t}$, with a conditional mean of zero before specifying our generalised autoregressive conditional heteroscedasticity (GARCH) for the variance. One common method to produce an uncorrelated process in the daily spot prices is to assume that the level of prices follow an $\operatorname{AR}(1)$ process. The following conditional mean spot electricity price equation accommodates each electricity market's own price and its price lagged one period:

$$
p_{t}=\alpha_{0}+\alpha_{1} p_{t-1}+e_{t}
$$


where $p_{t}$ is the natural logarithm of the daily spot prices in the current period and $p_{t-1}$ is the natural logarithm of the daily spot price lagged one period, $\alpha_{0}$ represents the long-term drift coefficient and $\alpha_{1}$ is the degree of mean spillover effect across time, or put differently, whether the lagged spot price can be used to predict the current spot price and $e_{t}$, the random error or innovation at time $t$, is approximately distributed $e_{t} \sim N\left(0, h_{t}\right)$.

In our analysis, the available panel data consists of five interconnected cross-sections represented by the five regional markets over time. We estimate two Student panel $\operatorname{GARCH}(1,1)$ models incorporating assumptions of common and fixed effects. We believe this is justified by the relatively large number of time series observations and explanatory variables and the relatively small number of cross sectional observations. Many studies using GARCH analyses tend to include only the random walk in the conditional mean equation, as represented in Equation 1. The conditional mean equation can include explanatory variables such as the lagged price, demand, slack, interregional flow and generation type, and can be interpreted as a supply equation. As a comparison, Karakatsani and Bunn (2010) include explanatory variables in the conditional mean equation, including demand, slack, trend and seasonality, but only the ARCH, GARCH and asymmetry effects are included in the conditional variance equation.

We extend these studies by including flow of information in both the conditional mean and variance equations. The conditional mean or supply equation capturing the panel fixed effects is specified as:

$$
p_{i t}=\alpha_{0}+\sum_{i=2}^{5} \alpha_{i} R_{i}+\beta_{1} p_{i t-1}+\beta_{2} V O L_{i t}+\beta_{3} S L K_{i t}+\beta_{4} F L O W_{i t}+\sum_{i=1}^{6} \delta_{i} G E N_{i t}+e_{i t}
$$

where $R_{i}$ are dummy variables to capture each regional effect having values of 1 for $R_{2}$ (QLD) and 0 otherwise,... having values of 1 for $R_{5}$ (VIC) and 0 otherwise (NSW is the reference category, $V O L_{i t}$ is the contemporaneous volume of demand, $G E N_{i t}$ is the indicator of generation mix (BKCL, BNCL, OCGT, CCGT, HYDR and WIND), SLK $K_{i t}$ is the daily available slack, $F L O W_{i t}$ is the daily inter-regional flow, $\alpha_{\mathrm{i}}, \beta_{\mathrm{i}}$ and $\delta_{\mathrm{i}}$ are coefficients to be estimated, and all other variables are as previously defined. We use the Student GARCH model in both the common and fixed effects specifications to take account of the fat-tailed characteristics of Australian wholesale electricity prices (Giot and Laurent, 2003a and 2003b and Higgs and Worthington, (2005). The Student fixed effects GARCH process is defined as $e_{t}=h_{t} \varepsilon_{t}$ and $\varepsilon_{t} \sim$ iid $t(0,1, v)$ where and $v$ is the degrees of freedom. 
The final methodological requirement is to incorporate the arrival of exogenous information in the volatility generating process in Equation (3). As the incidence of the time varying conditional heteroskedasticity could be due to regional effects and an increase in the volume of demand, generation types, day-of-week and month-of-year effects following the simultaneous arrival of news information, the panel conditional variance equation is reformulated as:

$$
h_{i t}^{2}=\phi_{0}+\sum_{i=2}^{5} \phi_{i} R_{i t}+\gamma_{1} e_{i t-1}^{2}+\gamma_{2} h_{i t-1}^{2}+\gamma_{5} V O L_{i t}+\sum_{i=1}^{6} \eta_{i} G E N_{i t}++\sum_{i=2}^{7} \lambda_{i} W_{i}+\sum_{i=2}^{12} \varsigma_{i} M_{i}
$$

where $h_{i t}^{2}$ is the conditional variance of $e_{i t}$ at time $t, \gamma_{1}$ and $\gamma_{2}$ are coefficients that are associated with the degree of innovation from previous period, $e_{i t-1}^{2}(\mathrm{ARCH}$ term) and previous period's volatility spillover effects, $h_{i t-1}^{2}\left(\mathrm{GARCH}\right.$ term) respectively, $W_{i}$ are dummy variables for each of the day-of-week effect having values of 1 for $W_{2}$ (Tuesday) and 0 otherwise,... having values of 1 for $W_{7}$ (Sunday) and 0 otherwise and $M_{i}$ are dummy variables for each month-of-year effect having values of 1 for $M_{2}$ (February) and 0 otherwise, ... having values of 1 for $M_{12}$ (December) and 0 otherwise and $\phi_{i}, \gamma_{i}, \eta_{i} \lambda_{i}$ and $\zeta_{i}$ are coefficients. To avoid a multicollinearity trap, Sunday and January are the reference categories in the calendar effects and all other variables are as previously defined. The Student common effects GARCH model excludes the regional effects $R_{\mathrm{i}}$ variables in both equations (2) and (3).

\section{Empirical results}

The estimated coefficients, standard errors and $p$-values incorporated Huber-White's robust standard error corrections for unknown forms of heteroskedasticity are presented in Table 2. On the basis of the log-likelihood, Akaike Information Criterion (AIC) and Schwartz's Criteria (SC), the Student fixed effects GARCH process is a better specification than the Student common effects process. Accordingly, we only discuss the Student fixed effects GARCH results. The estimated coefficients for all parameters are significant at the 10 percent level of significance with the exception of $B K C L, H Y D R$ and FLOW in the conditional mean equation and $B N C L$ and WIND in the conditional variance equation. All estimated parameters conform to our a priori expectations.

To start with, the estimated coefficients, standard errors and $p$-values for the conditional mean equations for the Student fixed effects GARCH model are in the uppermost panel of 
Table 2. The average daily log price is 0.2974 . This indicates that the average equilibrium price is $\$ 1.35 / \mathrm{MWh}$ [ $\$ 1.35=\exp (0.2974)]$ for NSW, $\$ 1.08 / \mathrm{MWh}$ for QLD, \$1.40/MWh for SA, \$1.40/MWh for TAS and \$1.45/MWh for VIC. As a comparison, Higgs (2009) found the average daily price is $\$ 1.67 / \mathrm{MWh}$ for NSW, \$1.41/MWh for QLD, \$2.88/MWh for SA and $\$ 2.08 / \mathrm{MWh}$ for VIC. The electricity spot market exhibits significant own mean spillover from its own lagged electricity price where a $\$ 1.00 / \mathrm{MWh}$ increase in its own spot price will Granger cause an increase of $\$ 2.23 / \mathrm{MWh}(0.8066)$ in its price over the next day. As a comparison, Worthington et al. (2005) found only two of the five Australian spot electricity markets exhibit a positive significant own mean spillover from their own lagged electricity price.

A ten percent increase in $F L O W$ will increase the spot price by 0.047 percent. This suggests that as the daily inter-regional flow increases, the spot price will also increase. The SLK variable represents the excess daily available generation capacity. For a ten percent increase in $S L K$, the spot price will decrease by 0.956 percent, indicating that as excess capacity increases the price will decrease. The signs of both these coefficiencts correspond to their hypothesised signs, indicating that productive slack is associated with lower electricity prices and interregional flows with high electricity prices. In terms of generation mix, black and brown coal is associated with prices 7.2 percent and 7.9 percent lower than average prices, respectively. In contrast, combined- and open-cycle gas turbines are associated with prices that are 2.3 percent and 1.3 percent higher on average, respectively, while hydro generation is 0.9 percent higher and wind generation is 1.4 percent lower.

\section{<TABLE 2 HERE>}

Table 2 also presents the estimated coefficients, standard errors and $p$-values for the conditional variance equation. The spot prices in all regional markets are more volatile than NSW. The spot prices in SA (10.2312) and TAS (8.7221) are more volatile than that of VIC (5.3435) and QLD (3.2773). The estimated coefficient for the contemporaneous volume of demand of 0.4042 indicates a positive relationship. This would suggest that the role of new information in the form of demand load has a greater role of increasing price volatility. There also appears to be significant positive relationships between generation by $B K C L, O C G T$ and $H Y D R$ and spot price volatility. This would suggest that BKCL, OCGT and HYDR plants have a greater role of increasing price volatility. Whereas, the negative estimated coefficients for $B N C L, C C G T$ and WIND imply that these generators have a tendency of reducing price volatility. 
In terms of the day-of-the-week and month-of-the-year effects (results not shown) relative to Sunday, volatility in the interconnected regional market is highest on Monday then falling to a low on Tuesday and then progressively increasing through the week. A familiar price volatility pattern emerges with volatility being highest in September, November, December and January (summer) and lowest in the winter months. Similar results are found by Solibakke's (2002) that the price volatility in the Nordic spot electricity market increased though through summer. However, Hadsell et al. (2004) found that while calendar months exhibited different volatility behaviour in US electricity markets, none was unique with respect to magnitude or volatility. Higgs and Worthington (2005) showed volatility in the QLD and SA markets was highest on Monday, falling progressively through the week while price volatility was highest in June, July and August (winter) and December and January (summer).

The own-innovation or ARCH spillovers (0.6209) is significant indicating the presence of significant ARCH effects, while the lagged volatility or GARCH spillovers (0.1228) is smaller in magnitude. This suggests that the last period's volatility shocks in the spot electricity price have a lesser effect on its future volatility than the memory of previous surprises or innovations. Contrary to this finding, Higgs and Worthington (2005) generally found the GARCH effect was significantly larger than the ARCH effect for four of the five Australian electricity markets.

One important and well-founded characteristic of electricity spot prices is the tendency for volatility clustering to be found, such that large changes in spot prices are often followed by other large changes, and small changes in daily spot prices are often followed by yet more small changes. The implication of such volatility clustering is that volatility shocks today will influence the expectation of volatility in the future. The persistence coefficient is defined as the sum of the ARCH and GARCH effects. The persistence coefficient is less than one (0.7437), which implies that the interconnected markets experience a mean-reverting conditional volatility process in which the shocks are transitory in nature. As a comparison, Higgs and Worthington (2005) found the degree of persistence to be less than one for each of the Australian spot electricity markets, employing the skewed Student asymmetric power ARCH model. Higgs (2009) concluded that the persistence coefficient is less than one for NSW (0.9667), SA (0.7013) and VIC (0.9766). 


\section{Conclusion}

This study presents an analysis of electricity prices across the five Australian regional markets in the NEM. We use Student common and fixed effects GARCH regressions to evaluate the effects of a number of supply and demand factors on daily prices, including generation mix, but also interconnector flow, generation capacity, and seasonal factors. As expected, generation mix exerts a strong influence on electricity prices, with prices being generally lower with the use of brown and black coal and higher with the use of gas and renewable technologies, all of which have lower GHG emissions. This suggests the likelihood of higher wholesale prices as the electricity industry moves toward renewable energy targets in developing low-emission technologies such as gas and wind power. In other results, flow across the regional interconnectors generally increases prices while slack generation capacity generally serves to reduce prices.

Of course, this analysis ignores any allowance for the recently removed system of carbon taxation intended to reflect the contribution of both black and brown coal to GHG emissions and its replacement by a 'direct action' program comprising subsidies to larger GHG emitters. Throughout the sample period of analysis, the RET has also been in place, though this has been recently reviewed. Nonetheless, the expectation is that these policy changes will ultimately add to wholesale prices derived from these sources of generation. A final limitation is that in the last few years, and outside our chosen sample period, electricity demand decline and a situation of excess capacity has emerged in the NEM. It is then possible that our results would change were our analysis to extend to 2015 .

This well illustrates the dynamic characteristics of wholesale electricity markets. In this sense, while beyond the scope of the current paper, there are several possible suggestions for future research. One would be a change in specification such that the daily average or maximum temperature instead of the month would serve as the measure of seasonality. In addition, it may be interesting to incorporate a variable related to outages (forced and enforced), perhaps by adjusting the slack variable.

\section{References}

Australian Energy Market Operator (AEMO), 2015. http://www.aemo.com.au/. Accessed November 2015.

Bassett, G.W., Tam, M.S., Knight, K., 2002. Quantile models and estimators for data analysis. Metrika 55, 1726.

Becker, R., Hurn, S., Pavlov, V., 2007. Modelling spikes in electricity prices. Econ. Rec. 83, 371-382. 
Chan, K.F., Gray, P., 2006. Using extreme value theory to measure value-at-risk for daily electricity spot prices, Int. J. of Forecast. 22, 283-300.

De Vany, A.S., Walls, W.D., 1999a. Cointegration analysis of spot electricity prices: Insights on transmission efficiency in the western US, Energy Econ. 21, 435-448.

De Vany, A.S., Walls, W.D., 1999b. Price dynamics in a network of decentralized power markets, J. of Regul. Econ.15, 123-140.

Escribano, A., Pena, J.I., Villaplana, P., 2002. Modelling electricity prices: International evidence, Working Paper 02-27, Economics Series 08, Departmento de Economia, Universidad Carlos III de Madrid.

Fleming, D.A., Measham, T.G. 2015. Local economic impacts of an unconventional energy boom: The coal seam gas industry in Australia. Aust. J. of Agric. and Resour. Econ. 59 78-94.

Garnaut, R., 2011. Garnaut Climate Change Review: Update 2011, Update Paper 8: Transforming the electricity sector.

Giot, P., Laurent, S., 2003a. Market risk in commodity markets: A VaR approach. Energy Econ. 25, $435-457$.

Giot, P., Laurent, S., 2003b. Value-at-risk for long and short trading positions. J. of Appl. Econom. 18, 641664.

Global Roam, 2012. http://www.global-roam.com. Accessed November 2015.

Hadsell, L., Marathe, A., Shawky, H.A., 2004. Estimating the volatility of wholesale electricity spot prices in the US. Energy J. 25, 23-40.

Herbert, J., 2002. Power prices today: Growing more unpredictable. Public Util. Fort. 140, 28-35.

Higgs, H., 2009. Modelling price and volatility inter-relationships in the Australian wholesale spot electricity markets, Energy Econ. 31, 748-756.

Higgs, H., Worthington, A.C., 2005. Systematic features of high-frequency volatility in the Australian electricity market: intraday patterns, information arrival and calendar effects. Energy J. 26, 1-20.

Higgs, H., Worthington, A.C., 2008. Stochastic price modelling of high volatility, mean-reverting, spike-prone commodities: The Australian wholesale electricity market. Energy Econ. 30, 3172-3195.

Higgs, H., Worthington, A.C., 2010 Modelling spot prices in deregulated wholesale electricity markets: A selected empirical review, Energy Stud. Rev. 17, 1-25.

Karakatsani, N.V., Bunn, D.W., 2010. Fundamental and behavioural drivers of electricity price volatility. Stud. in Nonlinear Dyn. and Econom. 14, 1-40.

Koopman, S.J., Ooms, M., Carnero, M.A., 2007. Periodic seasonal reg-ARFIMA-GARCH models for daily electricity spot prices, J. of the Amer. Stat. Assoc. 102, 16-27.

Lucia, J.J., Schwartz, E.S., 2002. Electricity prices and power derivatives: Evidence for the Nordic power exchange, Rev. of Derivatives Res. 5, 5-50.

Robinson, T., 2000. Electricity pool series: A case study in nonlinear time series modelling, Appl. Econ. 32, $527-532$.

Simshauser, P., Nelson, T., 2013. The outlook for residential electricity prices in Australia's national electricity market in 2020. Elec. J. 26, 66-83

Solibakke, P., 2002. Efficient estimated mean and volatility characteristics for the Nordic spot electricity power market. Int. J. of Bus. 7, 17-35.

Worthington, A.C., Kay-Spratley, A., Higgs, H., 2005. Transmission of prices and price volatility in Australian electricity spot markets: a multivariate GARCH analysis. Energy Econ. 27, 337-350. 



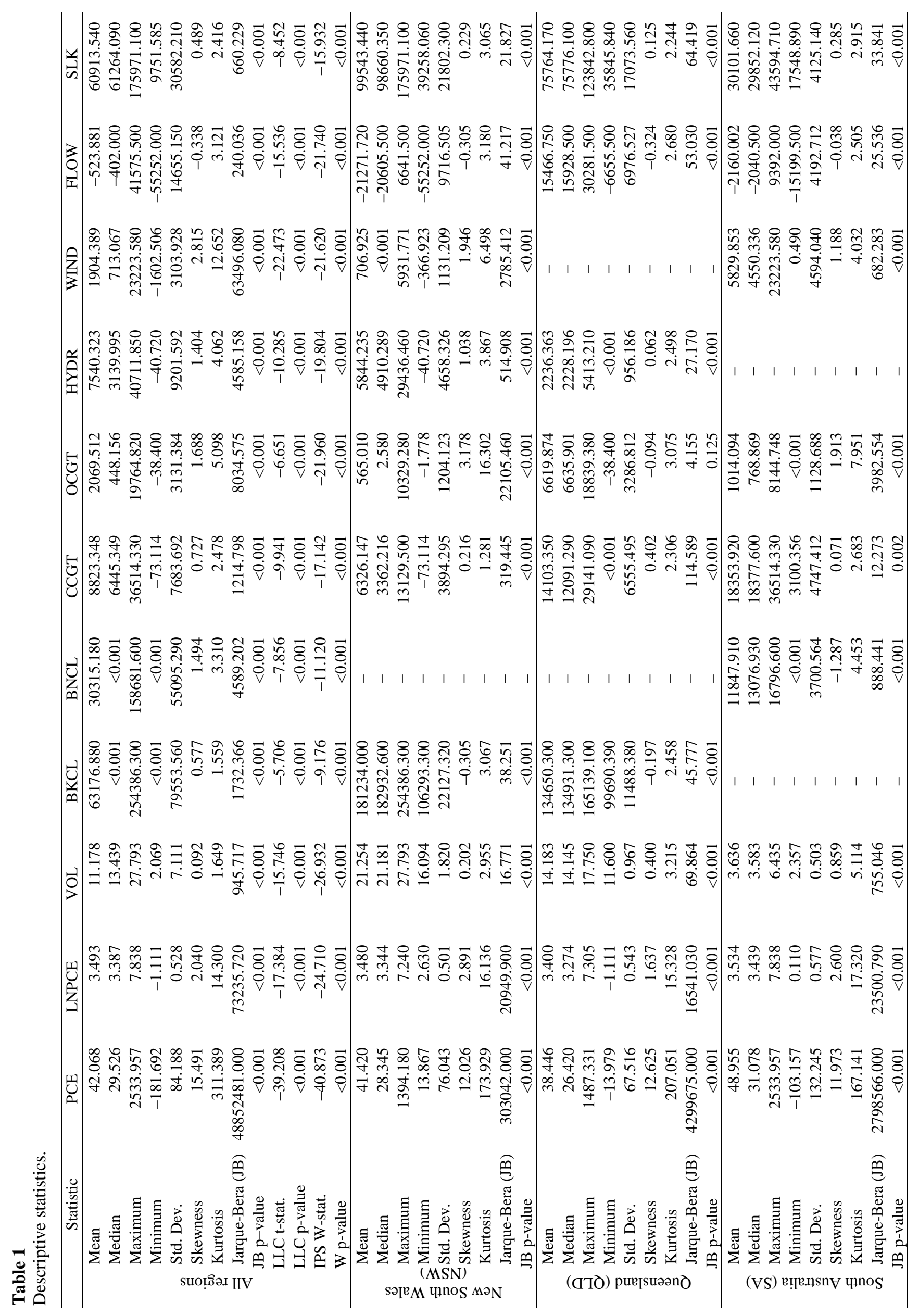




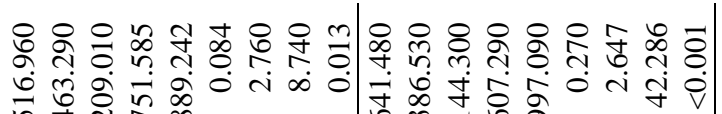

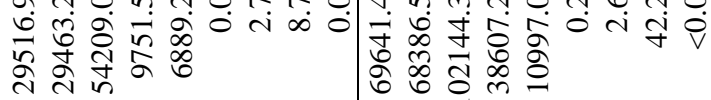

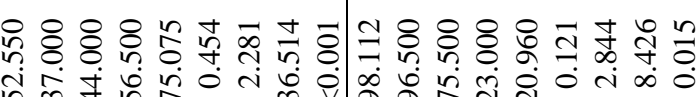

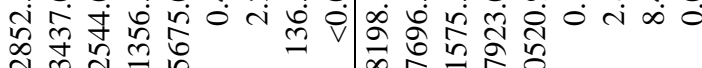

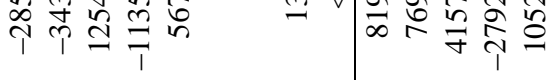

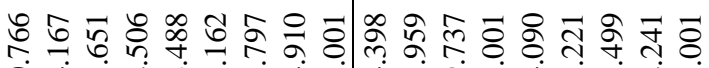

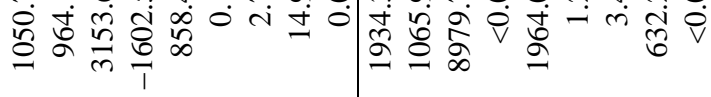

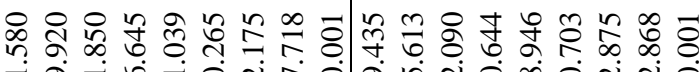

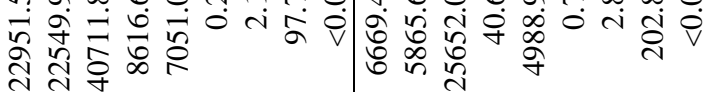

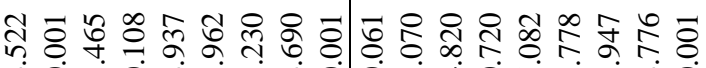

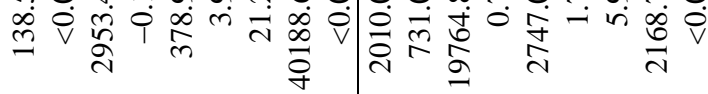

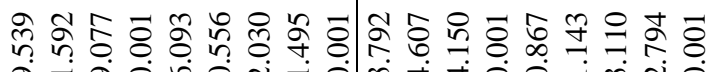

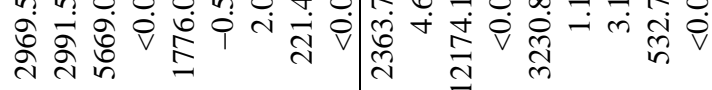

ช 8 응 \& N 슨

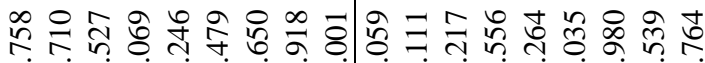

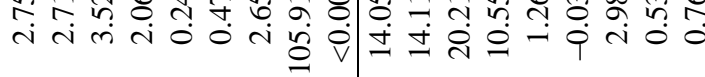

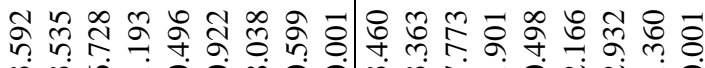
20000

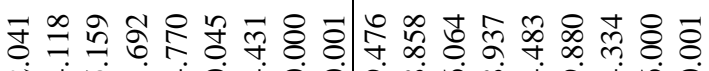

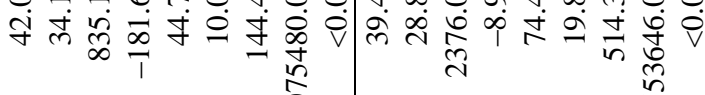

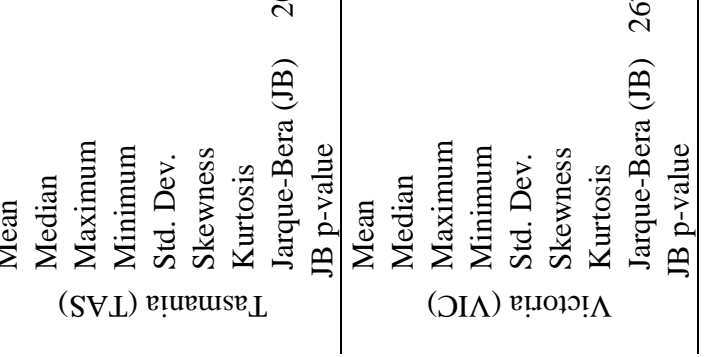


Table 2

Estimated regressions.

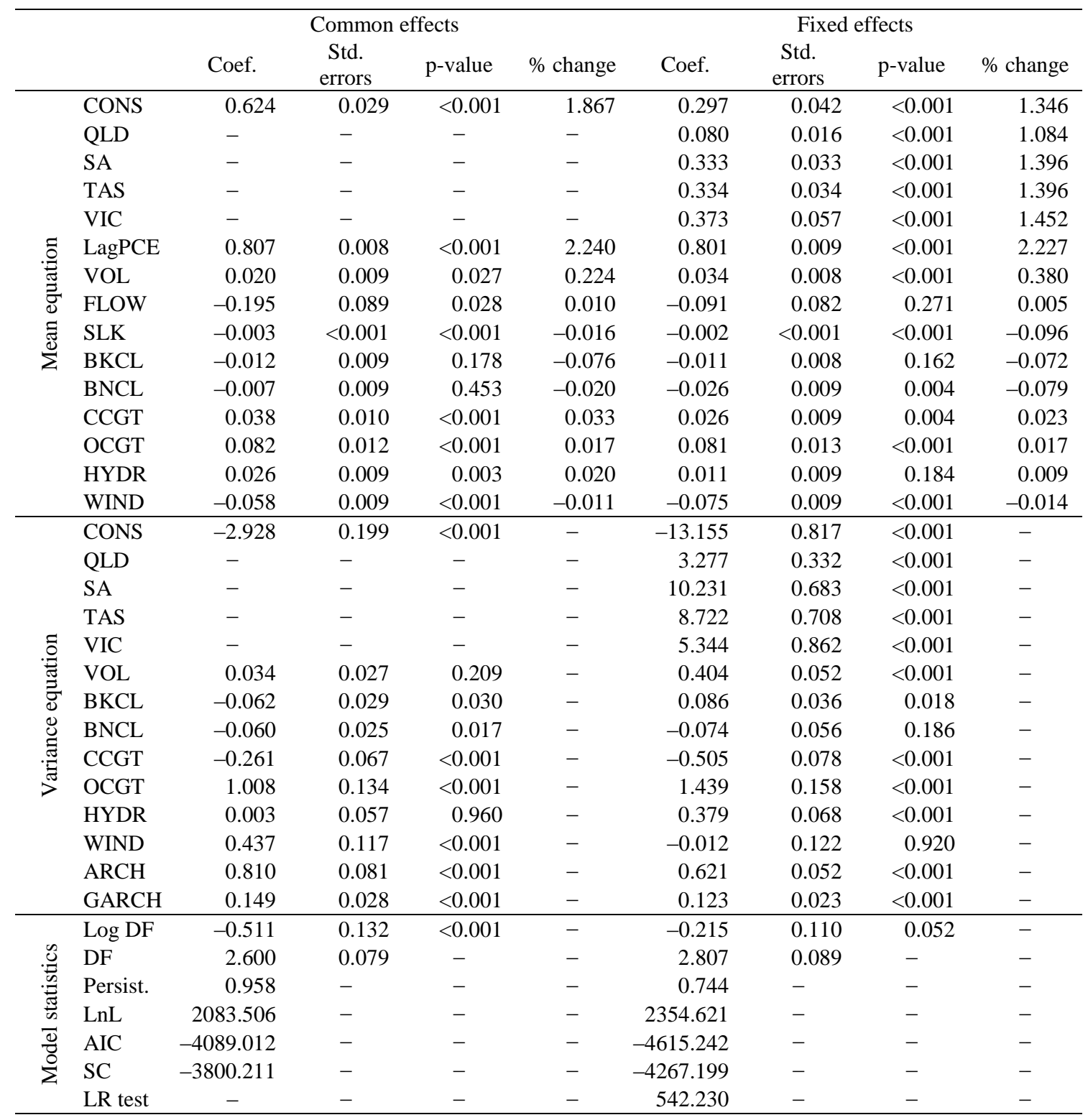

